\title{
Two split-time artificial insemination programs in suckled beef cows ${ }^{1,2}$
}

\author{
J. S. Stevenson, ${ }^{* 3}$ S. L. Hill,* D. M. Grieger, ${ }^{*}$ K. C. Olson,* \\ J. R. Jaeger,* J. Ahola, $\uparrow$ G. E. Seidel, $\$$ and R. K. Kasimanickam $§$
}

*Department of Animal Sciences and Industry, Kansas State University, Manhattan 66506-0201, $†$ Department of Animal Sciences, Colorado State University, Fort Collins 80523; $\$$ Department of Biomedical Sciences, Colorado State University, Fort Collins 80523; §Department of Veterinary Clinical Sciences, Washington State University, Pullman 99164

\begin{abstract}
Our objective was to determine which of 2 split-time AI programs applied to suckled beef cows would result in greater pregnancy risk. Suckled beef cows $(n=1,062)$ at 12 locations in 4 states $(C O$, $\mathrm{KS}, \mathrm{MY}$, and WA) were enrolled. Cows were treated on $\mathrm{d}-7$ with a progesterone insert concurrent with $100 \mu \mathrm{g}$ GnRH and on 0 with $25 \mathrm{mg} \mathrm{PGF}_{2 \alpha}$ plus removal of the insert. Estrus-detection patches were affixed to cows at insert removal. The study was designed as a completely randomized experiment of 2 treatment combinations. Within location and balanced for parity (primiparous vs. multiparous), cows were assigned randomly to 2 treatment times ( 55 vs. $65 \mathrm{~h}$ after CIDR insert removal) at which time estrus-detection patches were assessed. Estrus was defined to have occurred when an estrusdetection patch was $>50 \%$ colored (activated). Cows determined to be in estrus were inseminated at either 55 or $65 \mathrm{~h}$, whereas the residual nonestrous cows in both treatment times received GnRH at 55 or $65 \mathrm{~h}$ but were inseminated $20 \mathrm{~h}$ later at 75 or $85 \mathrm{~h}$, respectively. Pregnancy outcomes were determined at $36 \mathrm{~d}$ after AI and at the end of the breeding season. Thus, pregnancy outcomes of interest were compared between the $55+$
\end{abstract}

75-h treatment combination and that of the $65+85-\mathrm{h}$ combination. Expression of estrus was greater $(P=$ $0.001)$ by $65 \mathrm{~h}$ after $\mathrm{PGF}_{2 \alpha}$ than by $55 \mathrm{~h}(62.0 \%$ vs. $41.9 \%$ ), respectively, and this proportion was influenced by parity (time x parity interaction; $P=0.006$ ). As a result, proportionally more $(P<0.001)$ cows received the timed AI at 75 than $85 \mathrm{~h}(59.4 \%$ vs. $40.6 \%)$. Similar proportions of cows not in estrus by 55 or $65 \mathrm{~h}$ were detected in estrus by 75 or $85 \mathrm{~h}(40.1 \%$ vs. $39.3 \%$ ), respectively. The cumulative proportion of cows in estrus by $75 \mathrm{~h}$ was less $(P<0.001)$ than that by $85 \mathrm{~h}(66.7 \%$ vs. $76.7 \%)$, respectively. Pregnancy risks at $36 \mathrm{~d}$ differed among treatments, with cows detected in estrus and inseminated at 55 or $65 \mathrm{~h}$ having greater pregnancy risks than their time-inseminated herd mates at 75 or $85 \mathrm{~h}(62.3 \%$ vs. $49.7 \%)$, respectively. Overall pregnancy risk for cows in the $65+85$-h treatment combination was greater at $36 \mathrm{~d}$ than for cows in the $55+75$-h treatment combination $(61.0 \%$ vs. $51.4 \%)$, respectively. We conclude that the $65+85$-h treatment combination produced more pregnancies than the $55+$ 75-h combination, but its implementation may be somewhat less convenient in terms of cow handling times.

Key words: beef cattle, CIDR, estrus, split-time AI

\section{INTRODUCTION}

\footnotetext{
${ }^{1}$ We gratefully acknowledge the donations of Factrel, Lutalyse, and CIDR inserts from Roger Saltman (Zoetis, Florham Park, NJ) and Boyd Dingus (Estrotect, Spring Valley, WI) for supplying the estrus-detection patches.

${ }^{2}$ Contribution number 17-355-J from the Kansas Agricultural Experiment Station, Manhattan, KS.

${ }^{3}$ Corresponding author: jss@ksu.edu

Received June 9, 2017.

Accepted September 4, 2017.
}

Successful programs to manipulate estrus and ovulation to maximize pregnancy outcomes in suckled beef cattle have been developed (Lamb and Mercadante, 2016) to limit animal handling and eliminate detection of estrus to provide opportunities to incorporate AI to start the breeding season. The most successful and consistent scheme employs an intravaginal progesterone insert (control internal drug release or CIDR) for $7 \mathrm{~d}$ concurrent with GnRH treatment, and on removal 
of the insert, injection of $\mathrm{PGF}_{2 \alpha}$, followed by timed AI at 60 to $66 \mathrm{~h}$ concurrent with a second dose of $\mathrm{GnRH}$ (CO-synch + CIDR; Lamb and Mercadante, 2016).

Inseminating cows after expressed estrus increases pregnancy risk compared with cows that do not display estrus in a timed AI program (Richardson et al., 2016; Hill et al., 2016a,b). Identification of estrus can be accomplished easily by using estrus-detection patches (Hill et al., 2016a), thus facilitating timing of AI to meet herd-specific situations. Varying AI timing has increased pregnancy risk in some (Markwood et al., 2014; Thomas et al., 2014a; Hill et al., 2016a,b), but not all studies (Thomas et al., 2014b).

Employing detection of estrus to optimally time AI relative to detected estrus rather than using 1 planned fixed-time AI for all cows was tested (i.e., split-time AI). In 2 separate experiments, estrus was detected by using estrus-detection patches at either 60 or $65 \mathrm{~h}$ after $\mathrm{PGF}_{2 \alpha}$ and $\mathrm{AI}$ was conducted for cows in estrus. Residual cows received a fixed-time AI at either 75 or $84 \mathrm{~h}$, respectively (Hill et al. 2016a,b). Administering GnRH to cows already detected in estrus at 60 or $75 \mathrm{~h}$ did not improve pregnancy risk, and administering GnRH at 60 or 75 h to cows not yet in estrus only improved pregnancy risk in cows that did not come into estrus during the interim before timed AI occurred at 75 or 84 h, respectively (Hill et al., 2016b).

Our objective was to determine in 1 experiment which time combination for split-time AI would maximize pregnancy risk in suckled beef cows: $55 \mathrm{~h}$ (AI cows in estrus) $+75 \mathrm{~h}$ (receive GnRH at $55 \mathrm{~h}$ and $\mathrm{AI}$ at $75 \mathrm{~h}$ ) or $65 \mathrm{~h}$ (AI cows in estrus) $+85 \mathrm{~h}$ (receive GnRH at $65 \mathrm{~h}$ and $\mathrm{AI}$ at $85 \mathrm{~h})$.

\section{MATERIALS AND METHODS}

The Kansas State University Animal Care and Use Committee approved all experimental procedures (protocol 3392). Suckled beef cows $(n=1,062)$ of mixed parity at 12 locations in 4 states were enrolled in the experiment in 2016. Characteristics by location including breed composition, percentage of primiparous cows, days postpartum at AI, and BCS are summarized (Table 1). Cows grazed native pastures during the treatment and AI period.

Cows were enrolled in a CO-Synch program plus a progesterone (1.38 g)-impregnated intravaginally placed insert (CIDR; Zoetis, Florham Park, NJ): GnRH + CIDR on d-7, CIDR insert removal + $\mathrm{PGF}_{2 \alpha}$ on $\mathrm{d} 0$ at which time estrus-detection patches (Estrotect, Spring Valley, WI) were affixed to the tail head of all cows according to manufacturer's recommendation. Dose of GnRH ( $2 \mathrm{~mL}$ Factrel i.m.; Zoetis) was $100 \mu \mathrm{g}$. Dose of $\mathrm{PGF}_{2 \alpha}$ was $25 \mathrm{mg}$ (2 mL Lutalyse
Table 1. Selected characteristics of suckled beef cows enrolled in the experiment

\begin{tabular}{|c|c|c|c|c|c|c|}
\hline Location ${ }^{1}$ & Breed $^{2}$ & $n$ & $\begin{array}{c}2 \text { yr. old } \\
(\%)\end{array}$ & $\begin{array}{c}\text { Days postpar- } \\
\text { tum at } \mathrm{AI}^{3}\end{array}$ & $\mathrm{BCS}^{3}$ & $\begin{array}{c}\text { Pregnancy } \\
\text { risk }^{4}, \%\end{array}$ \\
\hline $\mathrm{CO}-1$ & $\mathrm{~A}, \mathrm{H}$ & 75 & 31 & $156 \pm 23$ & $5.2 \pm 0.8$ & 62.7 \\
\hline $\mathrm{CO}-2$ & A & 150 & 27 & $77 \pm 9$ & - & 61.3 \\
\hline $\mathrm{CO}-3$ & A & 169 & 44 & $73 \pm 24$ & - & 63.3 \\
\hline KS-1 & A cross & 45 & 20 & $82 \pm 16$ & $5.7 \pm 0.5$ & 46.7 \\
\hline KS-2 & A cross & 44 & 27 & $83 \pm 14$ & $5.4 \pm 0.4$ & 29.5 \\
\hline KS-3 & $\mathrm{A} \times \mathrm{H}$ & 64 & 62 & $77 \pm 15$ & $6.0 \pm 0.8$ & 43.7 \\
\hline KS-4 & A cross & 75 & 16 & $69 \pm 16$ & $5.4 \pm 0.5$ & 65.8 \\
\hline KS-5 & A cross & 61 & 28 & $75 \pm 17$ & $5.1 \pm 0.5$ & 63.9 \\
\hline KS-6 & $\mathrm{A} \times \mathrm{H}$ & 101 & 0 & $75 \pm 18$ & $6.0 \pm 0.8$ & 54.3 \\
\hline MT-1 & A & 108 & 24 & $75 \pm 15$ & $4.8 \pm 0.6$ & 69.2 \\
\hline WA-1 & A cross & 70 & 0 & $59 \pm 10$ & $6.2 \pm 1.1$ & 71.4 \\
\hline WA-2 & A & 100 & 0 & $59 \pm 10$ & $6.2 \pm 0.7$ & 63.0 \\
\hline
\end{tabular}

${ }^{1}$ Cows at 12 locations in 4 states were enrolled.

${ }^{2} \mathrm{~A}=$ Angus and $\mathrm{H}=$ Hereford.

${ }^{3}$ Mean \pm SD.

${ }^{4}$ Assessed at 33 to $45 \mathrm{~d}($ median $=36 \mathrm{~d})$ after AI.

HighCon i.m.; Zoetis). Body condition scores (1 = thin; 9 = obese; Bellows et al., 1982) were assigned on $\mathrm{d}-7$ by trained evaluators in all but 2 locations.

The study was designed as a completely randomized experiment of 2 treatment combinations (Fig. 1). Within location and balanced for parity (primiparous vs. multiparous), cows were assigned randomly to 2 treatment times (55 vs. $65 \mathrm{~h}$ after CIDR insert removal). At 55 or $65 \mathrm{~h}$, estrus-detection patches were assessed. Estrus was defined to have occurred if patches were $>50 \%$ colored. Cows determined to be in estrus were inseminated at either 55 or $65 \mathrm{~h}$, whereas the residual nonestrous cows in both treatment times received $\mathrm{GnRH}$ at 55 or $65 \mathrm{~h}$ and were inseminated $20 \mathrm{~h}$ later at 75 or $85 \mathrm{~h}$, respectively. To facilitate inseminations (AI based on estrus or at a fixed time) at only 2 times, CIDR inserts were removed, $\mathrm{PGF}_{2 \alpha}$ injection, and application of estrus-detection patches in the 65-h treatment were removed $10 \mathrm{~h}$ before those in the $55-\mathrm{h}$ treatment. The 2 treatment combinations, therefore, consisted of the $55+75-\mathrm{h}$ and the $65+85$-h combinations with inseminations based on estrus occurring at either 55 or $65 \mathrm{~h}$ and their peer herd mates not in estrus at 55 or $65 \mathrm{~h}$ inseminated $20 \mathrm{~h}$ later at 75 or $85 \mathrm{~h}$, respectively.

Activated patches were removed from cows in estrus at 55 or $65 \mathrm{~h}$ at the time of AI. Patches on remaining cows were assessed at 75 or $85 \mathrm{~h}$ when cows received their timed AI, thus allowing a determination of the number of cows showing estrus during the 20 -h period after GnRH was administered to nonestrous cows before they were inseminated at 75 or $85 \mathrm{~h}$. Artificial insemination sires $(n=43)$ and technicians $(n=14)$ were generally 


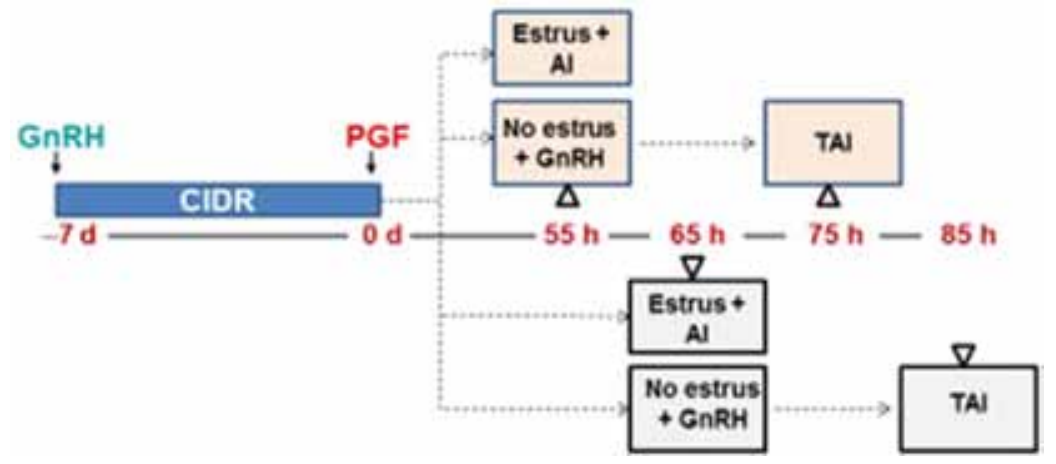

Figure 1. Experimental design of treatments employed in the experiment. Cows were enrolled in a CO-Synch + CIDR program (GnRH + CIDR on $\mathrm{d}-7$, CIDR insert removal $+\mathrm{PGF}_{2 \alpha}+$ fitted with estrus-detection patches on $\mathrm{d} 0$ ). Cows assigned to have their patches "read" ( $>50 \%$ activation) at either 55 or $65 \mathrm{~h}$ after CIDR insert removal. Cows with activated patches were then inseminated at either 55 or $65 \mathrm{~h}$. The residual nonestrous cows in both groups received GnRH at 55 or $65 \mathrm{~h}$ but were inseminated at 75 or $85 \mathrm{~h}$, respectively. CIDR $=$ controlled internal drug release insert containing $1.38 \mathrm{~g}$ of progesterone; $\mathrm{GnRH}=$ gonadotropin-releasing hormone; $\mathrm{PGF}=$ prostaglandin $\mathrm{F}_{2 \alpha} ; \mathrm{TAI}=$ timed artificial insemination .

unique to their location; however, a few technicians and sires were common to several locations within state.

No sooner than 1 wk after AI, cows were exposed to natural service sires for a total breeding season of 45 to $60 \mathrm{~d}$. A positive pregnancy outcome via transrectal ultrasonography required presence of an embryo with a visible heart beat at d 36 after AI (mean $=36.0 \pm 0.1 \mathrm{~d}$; range of 32 to $45 \mathrm{~d}$ ). A final pregnancy diagnosis was determined via transrectal ultrasonography or transrectal palpation no sooner than $35 \mathrm{~d}$ after the end of the breeding season. Pregnancy loss was defined as those cows pregnant at $36 \mathrm{~d}$ after AI, but not at the appropriate stage of pregnancy at the time of the final pregnancy diagnosis.

\section{Statistical Analyses}

All binomial variables were analyzed using logistic regression by applying procedure GLIMMIX $($ METHOD $=$ LAPLACE; ILINK = LOGIT; DIST $=$ BINOMIAL SOLUTION ODDSRATIO; SAS Inst. Inc., Cary, NC). Proportions of cows detected in estrus by 55 or $65 \mathrm{~h}$, during the 20-h interim until 75 or $85 \mathrm{~h}$, respectively, and total detected in estrus were analyzed. Estrus-detection risk at the times of 55 vs. $65 \mathrm{~h}$ were compared in one model and that for the times of $75 \mathrm{vs}$. $85 \mathrm{~h}$ were compared in a second model. The model included the fixed effects of time ( 55 vs. 65 h or 75 vs. 85 h), parity (primiparous vs. multiparous), interaction of time and parity, days postpartum as a continuous random variable, and location as a random effect. A second set of models was applied including cows from 10 locations that also included the continuous variable of BCS.

The binomial outcomes of pregnancy at $36 \mathrm{~d}$ after AI, final pregnancy risk at the end of the breeding season, and intervening pregnancy loss were analyzed using logistic regression in procedure GLIMMIX as described previously. Two models were constructed: one that included $\mathrm{AI}$ at all 4 times $(55,65,75$, and $85 \mathrm{~h})$ and a second with the treatment combinations of $55+75$ vs. $65+85 \mathrm{~h}$. Included in the models were the fixed effects of parity, interaction of time and parity or treatment combination and parity, days postpartum as a continuous random variable, and location as a random effect. Subsequent similar models also were constructed to include the continuous variable of $\mathrm{BCS}$ at 10 locations.

\section{RESULTS}

\section{Location Characteristics}

Summarized in Table 1 are location characteristics of 1,046 cows enrolled at the 12 locations in 4 states at which the experiment was conducted. The cows were Angus-based, including both purebreds and crosses of Angus. Cows at all locations calved during the spring, but at one location (CO-1), the spring-calving cows were moved to a fall-breeding program. As expected, resulting pregnancy risks varied $(P<0.001)$ among locations (Table 1). Actual insemination times were: $55 \mathrm{~h}$ (mean and range $=54.5 \mathrm{~h} ; 53.6$ to $55.8 \mathrm{~h}$ ), $65 \mathrm{~h}$ $(64.6 \mathrm{~h} ; 63.7$ to $66.0 \mathrm{~h}), 75 \mathrm{~h}(74.4 \mathrm{~h} ; 73.6$ to $75.5 \mathrm{~h})$, and $85 \mathrm{~h}(84.7 \mathrm{~h} ; 83.1$ to $85.5 \mathrm{~h})$.

\section{Expression of Estrus}

Expression of estrus was greater $(P=0.001)$ by 65 $\mathrm{h}$ after $\mathrm{PGF}_{2 \alpha}$ than by $55 \mathrm{~h}$ (Fig. 2), and this proportion was influenced by parity (time $\mathrm{x}$ parity interaction; $P=0.006$ ). By $55 \mathrm{~h}$, fewer primiparous than multiparous cows were in estrus, whereas no differences in those proportions were detected between parity groups by $65 \mathrm{~h}$. As a result, proportionally more $(P<0.001)$ cows received the timed AI at 75 than $85 \mathrm{~h}(59.4 \%$ vs. $40.6 \%$ ). Similar proportions of cows not in estrus by 55 or $65 \mathrm{~h}$ were detected in estrus by 75 or $85 \mathrm{~h}(40.1 \%$ vs. $39.3 \%$ ), respectively. As expected, the total proportion 


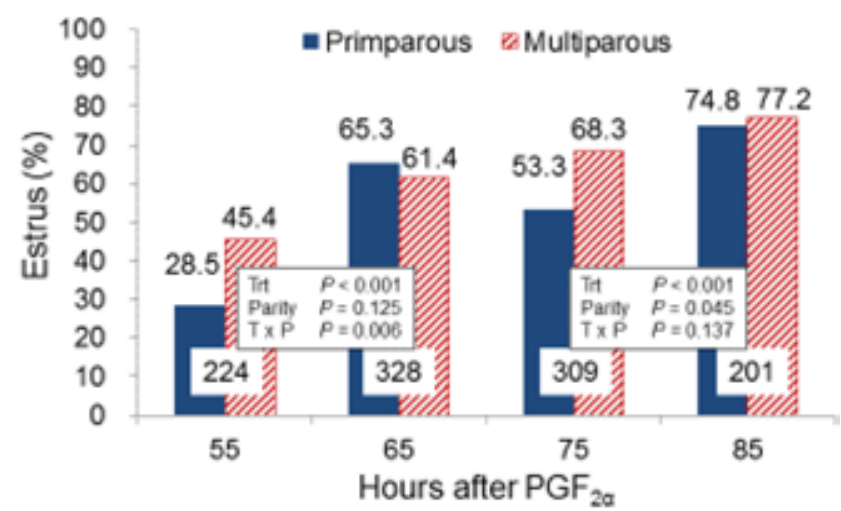

Figure 2. Proportions of cows interpreted to be in estrus by 55, 65, 75 , and $85 \mathrm{~h}$ after removal of a CIDR insert and injection of $\mathrm{PGF}_{2 \alpha}$ in primiparous and multiparous suckled beef cows. Cows in the 75- and 85-h times were treated with GnRH $20 \mathrm{~h}$ earlier, respectively.

of cows in estrus by $75 \mathrm{~h}$ was less $(P<0.001)$ than that by $85 \mathrm{~h}$ (Fig. 2). These proportions were affected by parity $(P=0.045)$, with more multiparous than primiparous cows showing estrus. No interaction of treatment and parity, however, was detected $(P=0.137)$ in the previous analysis. Body condition did not affect $(P=$ 0.12 ) expression of estrus in the current study.

\section{Pregnancy Outcomes}

Of cows in estrus $(n=500)$ by 55 or 65 h (inseminated at either 55 or $65 \mathrm{~h}$ ), pregnancy risk was greater $(P<0.001$; Table 2$)$ compared with cows not in estrus $(n=549)$ by those times (inseminated at 75 or $85 \mathrm{~h})$, respectively. Of cows not in estrus $(n=198)$ by 55 or $65 \mathrm{~h}$, but showed estrus by 75 or $85 \mathrm{~h}$, respectively, pregnancy risks were greater $(P<0.001)$ for cows expressing estrus than for cows not showing estrus $(n=302)$ during that 20 -h period $(66.7 \%$ vs. $42.7 \%$ ), respectively. Overall, regardless of when estrus occurred, pregnancy risk was greater $(P<0.001)$ for cows that showed estrus $(n=747)$ than for those not showing estrus and receiving the timed AI $(n=$ $302 ; 67.3 \%$ vs. $42.7 \%$ ).

Both actual and adjusted mean proportions of cows pregnant at $36 \mathrm{~d}$ after $\mathrm{AI}$, at the end of the breeding season, which included exposure to natural service sires, and intervening pregnancy loss are summarized in Table 2. Pregnancy risk at $36 \mathrm{~d}$ for estrous cows inseminated at $55 \mathrm{~h}$ did not differ from those estrous cows inseminated at $65 \mathrm{~h}$. Although estrous cows inseminated at $55 \mathrm{~h}$ had greater pregnancy risk than their nonestrous peers receiving the timed $\mathrm{AI}$ at $75 \mathrm{~h}$, that did not hold true for estrous cows inseminated at $65 \mathrm{~h}$ compared withtheir nonestrous peers receiving the timed $\mathrm{AI}$ at 85 h (contrasts: 55 vs. 65 h $[P=0.337] ; 55$ vs. 75 h $[P=$ $0.029] ; 65$ vs. 85 h $[P=0.113] ; 75$ vs. 85 h $[P=0.127])$.

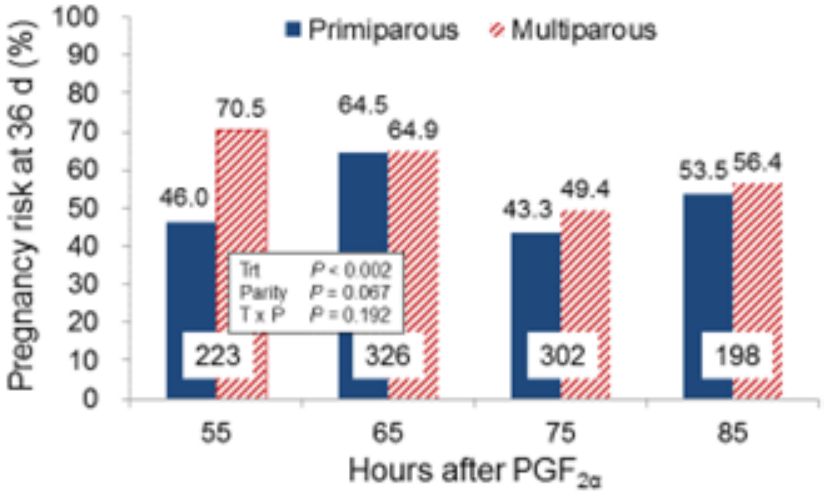

Figure 3. Pregnancy risk in primiparous and multiparous suckled beef cows at $36 \mathrm{~d}$ after artificial insemination by transrectal ultrasonography. Cows in the 55- and 65-h treatments were inseminated if estrus-detection patches were activated $(>50 \%)$ by 55 or $65 \mathrm{~h}$ after removal of a CIDR insert and injection of $\mathrm{PGF}_{2 \alpha}$. The residual nonestrous cows in both groups received $\mathrm{GnRH}$ at 55 or $65 \mathrm{~h}$ but were inseminated at 75 or $85 \mathrm{~h}$, respectively Thirteen cows were not present for this pregnancy diagnosis.

A more appropriate way to assess the programs is to examine the combined pregnancy risk for cows in the $55+75-\mathrm{h}$ treatment combination with those in the $65+85$-h treatment combination. Cows in the latter treatment combination had the greatest pregnancy risk at $36 \mathrm{~d}$ than the former (Table 2). This difference in pregnancy risk is explained partly by the proportionally greater number of cows receiving the timed $\mathrm{AI}$ in the $55+75$-h combination compared with those in the $65+85$-h combination ( $59.4 \%$ vs. $40.6 \%)$, respectively. In other words, the greater pregnancy risk of the $65+$ 85-h combination occurred because more cows were inseminated after having been detected in estrus and a tendency $(P=0.127)$ for greater pregnancy risk for cows receiving the timed AI at $85 \mathrm{~h}$ compared with $75 \mathrm{~h}$.

Pregnancy risks at $36 \mathrm{~d}$ tended $(P=0.067)$ to be less in primiparous than multiparous cows, but no interaction was detected $(P=0.192)$ between treatment and parity (Fig. 3). In 10 locations in which BCS was assessed, BCS did not significantly influence pregnancy risk at $36 \mathrm{~d}$. Cows with longer postpartum intervals to AI had greater pregnancy risk. For every 10 -d increase in days postpartum at $\mathrm{AI}$, pregnancy risk at $36 \mathrm{~d}$ increased by $3.1 \pm 0.1 \%(P=0.014)$ or $3.5 \pm 1.1 \%(P=0.026)$ depending whether the model included all 4 insemination times or the 2 treatment combinations, respectively.

Final pregnancy outcomes tended $(P=0.058)$ to be less in cows that received the timed AI at either 75 or $85 \mathrm{~h}$ (Table 2). In contrast, when the treatment combinations were examined, final pregnancy outcomes did not differ. As expected, final pregnancy outcomes were less $(P=0.001)$ in primiparous than multiparous cows (Fig. 4). Final pregnancy risks increased $(P=$ 0.001 ) by $3.4 \pm 0.7 \%$ (4 AI times) or by $3.5 \pm 0.7 \%$ (2 treatment combinations) for each $10-\mathrm{d}$ increase in 
Table 2. Pregnancy risk (PR) at $36 \mathrm{~d}$ after artificial insemination, final pregnancy risk at the end of the breeding season, and intervening pregnancy loss ${ }^{1}$

\begin{tabular}{|c|c|c|c|c|c|c|c|c|c|}
\hline & & \multicolumn{4}{|c|}{ Treatment ${ }^{2}$} & \multirow[b]{2}{*}{$P$-value } & \multicolumn{2}{|c|}{ Program $^{2}$} & \multirow[b]{2}{*}{$P$-value } \\
\hline & & 55 & 65 & 75 & 85 & & $55+75$ & $65+85$ & \\
\hline \multirow[t]{3}{*}{ PR at $36 \mathrm{~d}$} & $n$ & 223 & 326 & 302 & 198 & & 525 & 524 & \\
\hline & Actual, ${ }^{3} \%$ & 66.8 & 68.6 & 49.7 & 56.1 & & 57.7 & 62.8 & \\
\hline & Adjusted, ${ }^{4} \%$ & 58.8 & 64.7 & 46.3 & 55.0 & 0.002 & 51.4 & 61.0 & 0.015 \\
\hline \multirow[t]{3}{*}{ Final $\mathrm{PR}^{5}$} & $n$ & 223 & 326 & 307 & 199 & & 530 & 525 & \\
\hline & Actual \% & 94.8 & 92.8 & 87.9 & 87.4 & & 90.0 & 92.0 & \\
\hline & Adjusted \% & 92.3 & 93.9 & 86.8 & 88.0 & 0.058 & 88.7 & 91.7 & 0.185 \\
\hline \multirow[t]{3}{*}{ Loss } & $n$ & 153 & 217 & 149 & 110 & & 302 & 327 & \\
\hline & Actual \% & 2.0 & 0.9 & 2.7 & 8.2 & & 2.3 & 3.4 & \\
\hline & Adjusted \% & 2.0 & 0.9 & 2.7 & 8.2 & 0.068 & 2.3 & 3.4 & 0.599 \\
\hline
\end{tabular}

${ }^{1}$ Mean percentages with different superscript letters differ $(P<0.05)$.

${ }^{2}$ Cows were enrolled in a CO-Synch + progesterone-impregnated insert (CIDR) program $\left(\mathrm{GnRH}+\mathrm{CIDR}\right.$ on $\mathrm{d}-7, \mathrm{CIDR}_{\text {insert removal }+\mathrm{PGF}} \mathrm{r}+\mathrm{fit}_{-}$ ted with estrus-detection patches on $\mathrm{d} 0$ ). Cows assigned to have their patches assessed ( $>50 \%$ activation) at either 55 or $65 \mathrm{~h}$ after CIDR insert removal. Cows with activated patches were then inseminated at either 55 or $65 \mathrm{~h}$. The residual nonestrous cows in both groups received GnRH at 55 or $65 \mathrm{~h}$ but were inseminated at 75 or $85 \mathrm{~h}$, respectively.

${ }^{3}$ Unadjusted raw mean percentages.

${ }^{4}$ Adjusted mean percentages resulting from logistic regression analyses. Contrasts: 55 vs. 65 h $(P=0.337) ; 55$ vs. 75 h $(P=0.029) ; 65$ vs. 85 h $(P=$ $0.113) ; 75$ vs. 85 h $(P=0.127)$.

${ }^{5} \mathrm{Six}$ cows not present for the first pregnancy diagnosis (PR at $36 \mathrm{~d}$ ) were present for the final pregnancy diagnosis.

postpartum days to AI. Body condition score influenced final pregnancy risk in locations in which it was assessed. For every unit increase in BCS, final pregnancy risk increased by $(P=0.001) 4.1 \pm 1.5 \%$ (4 AI times) to $4.4 \pm 1.5 \%$ ( 2 treatment combinations).

Although small, pregnancy losses between $\mathrm{AI}$ and the end of the breeding season tended $(P=0.058)$ to differ among treatments, but they did not differ between the 2 treatment combinations (Table 2), averaging less than $4 \%$. For every $10-\mathrm{d}$ increase in days postpartum at AI, pregnancy loss decreased $(P<0.001)$ by $-1.1 \pm 0.5 \%$ (4 AI times) to $-1.3 \pm 0.5 \%$ ( 2 treatment combinations).

\section{DISCUSSION}

Split-time AI programs that employ 2 insemination times determined by occurrence of estrus allow for a closer alignment of the LH surge (spontaneous or GnRH-induced), AI, and ovulation. Furthermore, cows that show estrus at either AI time have no need for exogenous GnRH because fertility is not improved when $\mathrm{GnRH}$ is administered to cows already in estrus (Hill et al., 2016b). This fact validates the accuracy of employing estrus-detection patches because pregnancy risk achieved is $>60 \%$, regardless of the time of AI. Occurrence of estrus assessed by patch readings increases as time after CIDR insert removal and $\mathrm{PGF}_{2 \alpha}$ increases: $55 \mathrm{~h}$ (42\%; current study), 60 h (46.3\%; Hill et al., 2016a), 65 to 66 h (69.4\%; current study; Hill et al., 2016b; Bishop et al., 2016; 2017), 75 h (69\%; current study; Hill et al., 2016a), 85 h (77.2\%; current study; Hill et al., 2016b), and 90 h (87\%; Bishop et al., 2016; 2017).

The current study demonstrated that $39 \%$ to $40 \%$ of cows in a split-time AI program displayed estrus between 55 and $75 \mathrm{~h}$ or between 65 and $85 \mathrm{~h}$. Previous studies demonstrated that between 60 and $75 \mathrm{~h}$, an additional 49\% showed estrus (Hill et al., 2016a) and $40 \%$ more showed estrus between 65 and 85 h (Hill et al., 2016b) after CIDR insert removal. These responses are consistent with other studies where $45 \%$ to $61 \%$ more cows showed estrus between 66 and $90 \mathrm{~h}$ (Bishop et al., 2016, 2017).

Split-time AI inconsistently improves overall pregnancy risk. We previously demonstrated that cows identified in estrus by $60 \mathrm{~h}$ and inseminated at that time had greater pregnancy risk than herd mates not in estrus by $60 \mathrm{~h}$ but inseminated at $60 \mathrm{~h}$ concurrent with GnRH treatment (64.2\% vs. 41.7\%; Hill et al., 2016a). In contrast, for cows not in estrus at $60 \mathrm{~h}$ but inseminated at $75 \mathrm{~h}$, regardless of whether GnRH was injected at 60 or $75 \mathrm{~h}$, pregnancy risk was $52.8 \%$ and $50 \%$, respectively; both of which were greater than that for nonestrous cows inseminated at $60 \mathrm{~h}$. In another study (Thomas et al., 2014b), comparing nonestrous cows inseminated at $66 \mathrm{~h}$ with nonestrous cows inseminated at $86 \mathrm{~h}(20 \mathrm{~h}$ after $\mathrm{GnRH})$, no difference in pregnancy risk was detected ( $45 \%$ vs. $50 \%$, respectively). In a similar study (Bishop et al., 2016), for cows not in estrus by $66 \mathrm{~h}$ (received $\mathrm{GnRH}$ at $66 \mathrm{~h}$ and were inseminated at $90 \mathrm{~h}$ ) compared with cows not in estrus by $66 \mathrm{~h}$ (received $\mathrm{GnRH}$ and $\mathrm{AI}$ at $90 \mathrm{~h}$ ), pregnancy risk (30\%) did not differ unless cows showed estrus between 66 and $90 \mathrm{~h}$, 


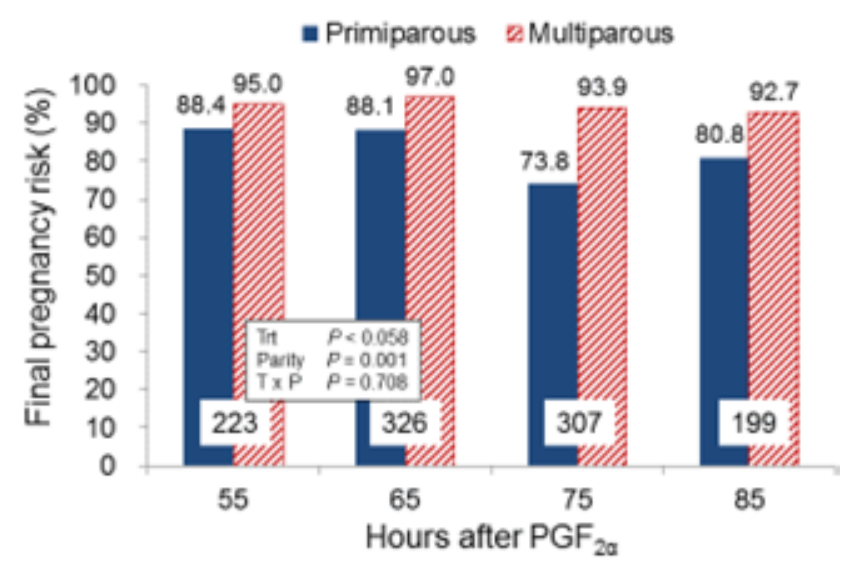

Figure 4. Final end of breeding season pregnancy risk in primiparous and multiparous suckled beef cows. Cows in the 55- and 65-h treatments were inseminated if estrus-detection patches were activated $(>50 \%)$ by 55 or $65 \mathrm{~h}$ after removal of a CIDR insert and injection of $\mathrm{PGF}_{2 \alpha}$. The residual nonestrous cows in both groups received GnRH at 55 or $65 \mathrm{~h}$ but were inseminated at 75 or $85 \mathrm{~h}$, respectively. Cows were exposed to cleanup bulls beginning $10 \mathrm{~d}$ after AI.

in which case pregnancy risk was $61 \%$. Similar results occurred in a third study (Bishop et al., 2017) in which pregnancy risk was $35 \%$ for nonestrous cows at $66 \mathrm{~h}$ (inseminated and treated with GnRH at $66 \mathrm{~h}$ ) compared with $38 \%$ for cows not detected in estrus but receiving $\mathrm{GnRH}$ and inseminated at $90 \mathrm{~h}$.

In all studies, however, when cows had shown estrus before AI, pregnancy risk was exceptional based on hours after CIDR insert removal and PGF $_{2 \alpha}$ : (1) estrus by $55 \mathrm{~h}$ (67\%; current study); (2) by $60 \mathrm{~h}(64.2 \%$; Hill et al., 2016a); (3) by 65 to 66 h (69\%, current study; $61 \%$, Hill et al., 2016b; 71\%, Thomas et al., 2014a,b; 60 to $63 \%$, Bishop et al., 2016; 58\%, Bishop et al., 2017); (4), by 75 h (67\%, current study; 65\%, Hill et al., 2016a); (5) by $85 \mathrm{~h}$ (67\%, current study; $65 \%$, Hill et al., 2016b; 63\%; Thomas et al., 2014b); or (6) by 90 h (60\%, Bishop et al., 2016; 63\%, Bishop et al., 2017).

Previous studies have identified conditions that alter the proportion of cows that display estrus at a given time or in total. Postpartum suckled cows that are anestrus at the onset of timed AI programs seem to display estrus earlier than their estrus-cycling herd mates (Geary et al., 2000; Stevenson et al., 2000; Busch et al., 2008). In contrast, cycling status of cows in a previous study did not influence the proportion of cycling and noncycling cows detected in estrus by 65 $\mathrm{h}$ after $\mathrm{PGF}_{2 \alpha}$ (Hill et al., 2016a). Although cows with a lesser BCS may be less likely to display estrus than cows with a greater BCS (Richardson et al., 2016), no effect of BCS was detected in the present study. In our previous study (Hill et al., 2016a), we noted that more primiparous cows with $\mathrm{BCS}>5$ were in estrus by 60 $\mathrm{h}$ after $\mathrm{PGF}_{2 \alpha}$ than older and thinner cows. In contrast, in a second study, occurrence of estrus by $65 \mathrm{~h}$ after the removal of the CIDR insert was neither affected by parity, BCS, nor cycling status (Hill et al., 2016b).

Although other split-time combinations have been tested (e.g., $60+75$ h, Hill et al., 2016a; $65+85$ h, Hill et al., 2016b; $66+86$ h, Thomas et al., 2014b; or $66+90$ h, Bishop et al., 2016; 2017), our study is the first to test concurrently 2 split-time programs in the same experiment at multiple sites. The $65+85$-h combination produced the greatest number of pregnancies compared with the $55+75$-h program. Cows not detected in estrus at 65 $\mathrm{h}$ compared with $55 \mathrm{~h}$, which received the timed AI at 85 $\mathrm{h}$ compared with $75 \mathrm{~h}$, tended to have greater pregnancy risk suggesting that timing of the second split-time AI was more optimal for cows not showing estrus by $65 \mathrm{~h}$ and inseminated at $85 \mathrm{~h}$. This improvement in pregnancy risk at $85 \mathrm{~h}$ likely occurred because $49 \%$ more cows that had shown estrus by 85 compared with $75 \mathrm{~h}$.

Advantages and disadvantages exist for applying a split-time AI program, so those choosing to employ such a scheme should consider their options. Employing split-time AI can reduce the risk associated with inseminating cows at 1 fixed time when conditions are less than ideal for optimal fertility because of inadequate holding facilities, weather conditions, inadequate body condition, and nutritional status of cows. Using split-time AI options requires more labor, the expense of using estrus-detection patches, and extra animal handling. In contrast, potential benefits include eliminating $\mathrm{GnRH}$ treatments to induce ovulation in cows already detected in estrus before AI (Hill et al., 2016b). Because pregnancy risk was consistently greater in cows that expressed estrus in the current study as well as in others (Richardson et al., 2016; Hill et al., 2016a,b) compared with those cows receiving the timed AI and not in estrus, sire selection might be altered to include sires with more desirable traits or those with greater trait accuracy compared with their peers bearing minimal desired traits to meet selection objectives, but of lesser cost for cows in which estrus status is not known at AI. Furthermore, when sire choice is of great importance to the user, utilizing estrus-detection patches for a timed AI program offers the advantage of different sire selection for those cows with activated vs. nonactivated patches when presented for the single scheduled timed AI at 60 to $66 \mathrm{~h}$. When using sexsorted semen, use of split-time AI facilitates increased pregnancy risk in suckled beef cows that received the delayed insemination time (Thomas et al., 2014a). In addition, knowledge of when estrus occurred at the 2 response times (e.g., $55+75 \mathrm{~h}$ or $60+85 \mathrm{~h}$ after CIDR insert removal) may be useful in cases to troubleshoot an unsuccessful breeding program (Bishop et al., 2017).

Easily employing split-time AI programs requires workable facilities to hold cow-calf pairs overnight un- 
less gathering cows the next day for the split-time AI is equally feasible. A small pasture trap or large pen to accommodate pairs is ideal for holding cow-calf pairs overnight. Having an available feed source, water, and shade during the period between split-AI times is optional, but may reduce some stress to cow-calf pairs. Location, pasture topography, daily temperatures, or ease of gathering pairs can limit or facilitate a split-time AI program. Although the $65+85 \mathrm{~h}$ treatment program resulted in more pregnancies, it may have its disadvantages in execution because of elevated ambient temperatures and gathering difficulties in afternoons rather than during cooler morning hours before either 55 or $65 \mathrm{~h}$.

We conclude that employing a split-time AI program at $65+85 \mathrm{~h}$ produced more pregnancies than the $55+75 \mathrm{~h}$ program because more cows in total were in estrus at the 65- and 85-h insemination times and fertility was greater in estrous than nonestrous cows.

\section{LITERATURE CITED}

Bellows, R. A., R. E. Short, and G. V. Richardson. 1982. Effects of sire, age of dam and gestation feed level on dystocia and postpartum reproduction. J. Anim. Sci. 55:18-27. doi:10.2527/ jas1982.55118x

Bishop, B. E., J. M. Thomas, J. M. Abel, S. E. Poock, M. R. Ellersieck, M. F. Smith, and D. J. Patterson. 2016. Split-time artificial insemination in beef cattle: I. Using estrous response to determine the optimal time(s) at which to administer $\mathrm{GnRH}$ in beef heifers and postpartum cows. Theriogenology 86:1102-1110. doi:10.1016/j.theriogenology.2016.03.043

Bishop, B. E., J. M. Thomas, J. M. Abel, S. E. Poock, M. R. Ellersieck, M. F. Smith, and D. J. Patterson. 2017. Split-time artificial insemination in beef cattle: III. Comparing fixed-time artificial insemination to split-time artificial insemination with delayed administration of GnRH in postpartum cows. Theriogenology. doi:10.1016/j.theriogenology.2017.04.046

Busch, D. C., D. J. Schafer, D. J. Wilson, D. A. Mallory, N. R. Leitman, J. K. Haden, M. R. Ellersieck, M. F. Smith, and D. J. Patterson. 2008. Timing of artificial insemination in postpartum beef cows following administration of the CO-Synch + controlled internal drug release protocol. J. Anim. Sci. 86:1519-1525. doi:10.2527/ jas.2008-0925
Geary, T. W., E. R. Downing, J. E. Bruemmer, and J. C. Whittier. 2000. Ovarian and estrous response of suckled beef cows to the Select Synch estrous synchronization protocol. Prof. Anim. Sci. 16:1-5.

Hill, S. L., D. M. Grieger, K. C. Olson, J. R. Jaeger, C. R. Dahlen, G. A. Bridges, F. Dantas, J. E. Larson, A. M. Muth-Spurlock, J. K. Ahola, M. C. Fischer, G. A. Perry, E. L. Larimore, T. L. Steckler, W. D. Whittier, J. F. Currin, and J. S. Stevenson. 2016a. Using estrus-detection patches to optimally time insemination improved pregnancy risk in suckled beef cows enrolled in a fixed-time artificial insemination program. J. Anim. Sci. 94:3703-3710. doi:10.2527/jas.2016-0469

Hill, S. L., D. M. Grieger, K. C. Olson, J. R. Jaeger, C. R. Dahlen, M. R. Crosswhite, N. Negrin Pereira, S. R. Underdahl, B. W. Neville, J. Ahola, M. C. Fischer, G. E. Seidel, and J. S. Stevenson. 2016b. Gonadotropin-releasing hormone increased pregnancy risk in suckled beef cows not detected in estrus and subjected to a split-time artificial insemination program. J. Anim. Sci. 94:3722-3728. doi:10.2527/jas.2016-0582

Lamb, G. C., and V. R. Mercadante. 2016. Synchronization and artificial insemination strategies in beef cattle. Vet. Clin. North Am. Food Anim. Pract. 32:335-347. doi:10.1016/j.cvfa.2016.01.006

Markwood, M. G., R. K. Peel, J. K. Ahola, G. E. Seidel, Jr., R. N. Funston, S. L. Lake, and J. C. Whittier. 2014. Effect of delaying time AI based on ESTROTECT ${ }^{\mathrm{TM}}$ patch status on pregnancy rates of nursing beef cows. Proc. West. Sect. ASAS 65:79-82.

Richardson, B. N., S. L. Hill, J. S. Stevenson, G. D. Gemechis, and G. A. Perry. 2016. Expression of estrus before fixed-time AI affects conception rates and factors that impact expression of estrus and the repeatability of expression of estrus in sequential breeding seasons. Anim. Reprod. Sci. 166:133-140. doi:10.1016/j.anireprosci.2016.01.013

Stevenson, J. S., K. E. Thompson, W. L. Forbes, G. C. Lamb, D. G. Grieger, and L. R. Corah. 2000. Synchronizing estrus and (or) ovulation in beef cows after combinations of $\mathrm{GnRH}$, norgestomet, and prostaglandin $\mathrm{F}_{2 \alpha}$ with or without timed insemination. J. Anim. Sci. 78:1747-1758. doi:10.2527/2000.7871747x.

Thomas, J. M., S. L. Lock, S. E. Poock, M. R. Ellersieck, M. F. Smith, and D. J. Patterson. 2014a. Delayed insemination of nonestrous cows improves pregnancy rates when using sex-sorted semen in timed artificial insemination of suckled beef cows. J. Anim. Sci. 92:1747-1752. doi:10.2527/jas.2013-7131

Thomas, J. M., S. E. Poock, M. R. Ellersieck, M. F. Smith, and D. J. Patterson. 2014b. Delayed insemination on non-estrous heifers and cows when using conventional semen in artificial insemination. J. Anim. Sci. 92:4189-4197. doi:10.2527/jas.2014-7827 